\title{
Research on the Correlation between English Scores in College Entrance Examination and Learning Strategies for Students of International Cooperative Education Program
}

\author{
Xingfeng Liu
}

\author{
School of management, Wuhan University of Technology
}

Keywords: Students of international cooperative education program; Learning strategies; English score in college entrance examination; Correlation analysis

\begin{abstract}
Wuhan University of Technology are taken as samples for the analysis and study of the correlation between English scores in college entrance examination and English learning strategies. The results have showed in four aspects: (1) students often use compensation and metacognitive strategies and less use memory strategy. (2) $75 \%$ of the students often use social strategies. (3)There is no obvious high correlation between English scores in college entrance examination and learning strategies. (4) The means of learning strategies used by students with high English scores win out over those with low English scores in college entrance examination as a whole.
\end{abstract}

\section{Introduction}

Researches of foreign language learning strategies have emerged in the late 20th century as the interdisciplinary product of foreign language teaching and psychology. Language learning strategies play an important role in the researches of second language acquisition. In 1966, Carton published Reasoning in Foreign Language Learning, which has become the first of its kind in the research of language learning strategies. In 1970s, Rubin (1975) has proposed the concept of language learning strategy ${ }^{[1]}$. Since then, researches on language learning strategies have aroused unprecedented attention in the field of linguistics and educational psychology. A great number of foreign language research pioneers (Rubin, 1975; Stern, 1975; Naiman et al, 1978) have made researches on the language strategies and summarized the common characteristics of successful language learners. Biggs, Bialystok, Entwistle, Saljo and other scholars have conducted researches on the relationship between learning strategies and academic scores in 1979 respectively. Until the 1980s, many foreign researchers have been still studying concept and classification system of language learning strategies (Rubin, 1981, 1987; Brown \& Palinscar, 1982; O'Grady et al, 1989; Skehan, 1989).

In the research of language learning strategies, determination of the operational definition of the concept and classification system structure is very important. Classification system of learning strategy that put forward by Bialystok (1978), O'Mallay \& Chamot [2] (1990) and Oxford [3] (1990) are most influential in western countries. In China, classification system of learning strategies proposed by Wen Qiufang [4] is also most representative.

Classification system of language learning strategies proposed by Oxford, is called "perhaps the most comprehensive so far" by the famous linguist Ellis [5]. Oxford (1990) has divided language learning strategies into direct and indirect strategies based on the relationship between language learning strategies and language materials. Direct strategies mean that there is a direct link between the strategies to be used and the language to be learned. Indirect strategies mean there is no direct link between strategies y to be used and language to be learned. These two categories of strategies comprise three subclasses respectively. Direct strategies include memory strategy, cognitive strategy and compensation strategy. Memory strategy is to set up the network of contacts, use image, sound and body movements, and review carefully, etc. Cognitive strategy refers to practice, receiving and imparting information, analyzing, reasoning, establishment of the appropriate rules of input and output information. Compensation strategy refers to overcoming the lack of knowledge of the 
language through reckoning during speaking and writing process. Indirect strategies include metacognitive strategy, affective strategy and social strategy. Metacognitive strategy means establishment of learning priorities, arranging, planning and evaluating the learning process and the results, etc. Affective strategy refers to reducing anxiety and tension, self-encouragement, understanding of self-emotion and so on. Social strategy refers to asking questions, teamwork collaboration and sympathy on other people, etc.

\section{Purpose of Research}

A great number of studies show that significant relationship exists between use of strategies and good language learners (Green and Oxford, 1995). Successful language learners can use a variety of strategies comprehensively and explain the purpose and reason in accordance with necessary tasks. The purpose of the study in this paper is to rely on the learning strategy theory and classification system proposed by Oxford (1990), study and analyze the correlation and features of the use of language strategies and English score in college entrance examination for international cooperative program students whose education system are $X+Y$ duration $(1+3,2+2,3+1)$. That is to say, the education system is X-year study in China and Y-year study in foreign country.

The aim in this paper is to explore three issues: (1) Is there any correlation between English scores in college entrance examination and English language learning strategies? (2)Is there any difference between students in the overall use of categories and subcategories of language strategies? (3) Is there any difference between students with high English scores and students with low English scores in the use of language strategies? We need to learn more about the importance of English strategies to provide a theoretical basis for foreign language teaching.

\section{Research Methods}

Samples of Survey. 300 students of school of international education of Wuhan University of education were tested for the test by means of random sampling method. Students aged from 18 to 20 years, have received more than seven years of formal English education. Among 300 questionnaires, there are 279 valid questionnaires and 21 unqualified questionnaires with the effective rate of $93 \%$.

Table 1 Questionnaire of study strategy

\begin{tabular}{r|l|l|l}
\hline & strategies & explanations & \multicolumn{1}{c}{ questions } \\
\hline 1 & $\begin{array}{l}\text { Memory strategy } \\
\text { Part A) }\end{array}$ & $\begin{array}{l}\text { Image, use of classification, pictures, sounds, words, cards, photos, and other body } \\
\text { movements, etc. }\end{array}$ & $\begin{array}{l}1-9 \\
(9 \text { in total) }\end{array}$ \\
\hline $\mathbf{2}$ & $\begin{array}{l}\text { Cognitive strategy } \\
\text { (Part B) }\end{array}$ & $\begin{array}{l}\text { receiving and disseminating information, reasoning, analysis, summary, general } \\
\text { practice, etc. }\end{array}$ & $\begin{array}{l}10-23 \\
(14 \text { in total) }\end{array}$ \\
\hline $\mathbf{3}$ & $\begin{array}{l}\text { Compensation } \\
\text { strategy(Part C) }\end{array}$ & $\begin{array}{l}\text { Context guessing, synonym expression, creating new words, gestures replacement, } \\
\text { selecting the topic, adjusting discourse, etc. }\end{array}$ & $\begin{array}{l}24-29 \\
(6 \text { in total })\end{array}$ \\
\hline $\mathbf{4}$ & $\begin{array}{l}\text { Meta-cognitive } \\
\text { strategy(Part D) }\end{array}$ & $\begin{array}{l}\text { Preparing in advance, directed attention, selective attention, self-management, } \\
\text { looking for opportunities to practice, error monitoring, delaying expression, } \\
\text { self-evaluation, etc. }\end{array}$ & $\begin{array}{l}30-38 \\
(9 \text { in total) }\end{array}$ \\
\hline $\mathbf{5}$ & $\begin{array}{l}\text { Affective } \\
\text { strategy(Part E) }\end{array}$ & Reducing anxiety, self-encouragement, self-reward, emotional control, etc. & $\begin{array}{l}39-44 \\
(6 \text { in total) }\end{array}$ \\
\hline $\mathbf{6}$ & $\begin{array}{l}\text { Social strategy } \\
\text { Part F) }\end{array}$ & $\begin{array}{l}\text { Active questions, cooperative learning, cultural concern, exchanging experience, } \\
\text { asking correction from other people, understanding other people, etc. }\end{array}$ & $\begin{array}{l}45-50 \\
(6 \text { in total })\end{array}$ \\
\hline
\end{tabular}

Research Tools. The research tool is strategy inventory for language learning (SILL for abbreviation) in the version for speakers of other Languages learning English) compiled by Oxford in1989. SILL is composed of 6 subscales and 50 self-narration questions, including two categories of direct strategy (memory strategy, cognitive strategy and compensation strategy) and indirect strategies (meta-cognitive strategy, affective strategy and social strategy)(see Table 1). In order to 
reflect the strategies used by learners directly, 5 grading measure system is taken for answers of the questionnaire (see Table 2).

Table 2 Design of questionnaire option

\begin{tabular}{l}
\hline $1=$ Never (totally inconsistent with my case) \\
\hline $2=$ Rarely (less in line with my case) \\
\hline $3=$ Sometimes (some in line with my case) \\
\hline $4=$ often (I often do so) \\
\hline $5=$ Always (every time I do so) \\
\hline
\end{tabular}

Method. Social science statistics software (SPSS) is used for statistical analysis. To ensure the accuracy and credibility of the results of the data obtained, total scale and subscales are analyzed. It is found that reliability coefficient of the total scale is greater than 0.93 , the reliability coefficient of each subscale of each test group is higher than 0.6, indicating stable nature of the scale.

\section{Results}

Correlation of using learning Strategies and English scores in college entrance examination in Table 3 and Table 4.

Table 3 Descriptive analysis of the use of studying strategies

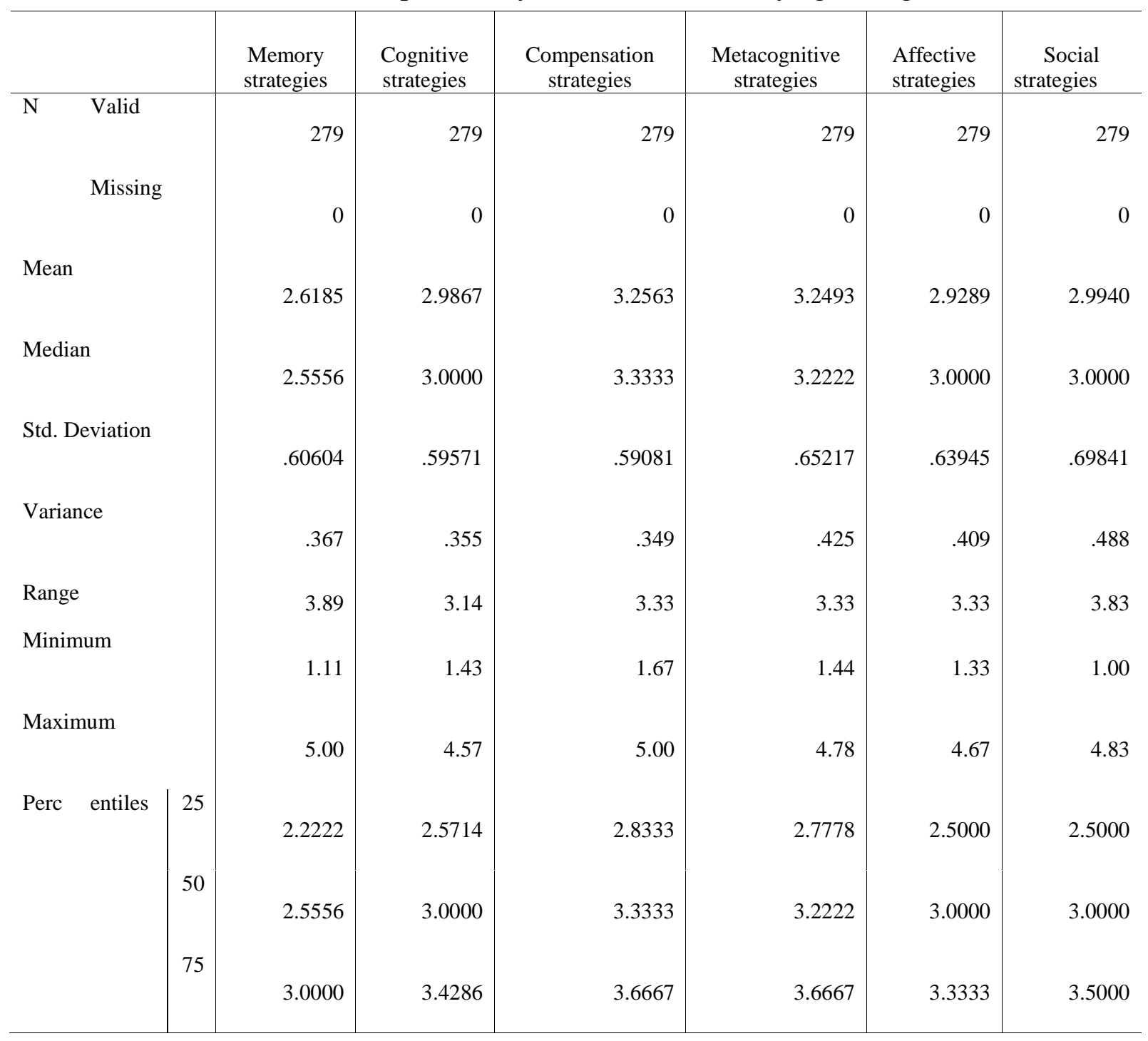


Table 4 Correlation analysis of studying strategies of English score in college entrance examination

\begin{tabular}{|c|c|c|c|}
\hline & & & Score in college entrance exam \\
\hline \multirow{23}{*}{$\begin{array}{r}\text { Spearman's } \\
\text { rho }\end{array}$} & Score in college & Correlation & 1000 \\
\hline & entrance exam & Coefficient & 1.000 \\
\hline & & Sig. (2-tailed) & \\
\hline & & & 279 \\
\hline & Memory strate & Correlation & .089 \\
\hline & & Coefficient & .089 \\
\hline & & Sig. (2-tailed) & .138 \\
\hline & & $\mathrm{N}$ & 279 \\
\hline & Cognitive strat & Correlation & $.167(* *)$ \\
\hline & egy & $\begin{array}{l}\text { Coefficient } \\
\text { Sig. (2-tailed) }\end{array}$ & .005 \\
\hline & & $\mathrm{N}$ & 279 \\
\hline & Compensation stra & $\begin{array}{l}\text { Correlation } \\
\text { Coefficient }\end{array}$ & $.198(* *)$ \\
\hline & & Sig. (2-tailed) & .001 \\
\hline & & $\mathrm{N}$ & 279 \\
\hline & Metacognitive strat & Correlation & $.174(* *)$ \\
\hline & & Sig. (2-tailed) & .004 \\
\hline & & $\mathrm{N}$ & 279 \\
\hline & Affective strategy & Correlation & .018 \\
\hline & & $\begin{array}{l}\text { Coefficient } \\
\text { Sig. (2-tailed) }\end{array}$ & 761 \\
\hline & & $\mathrm{N}$ & 279 \\
\hline & Social strategy & Correlation & .031 \\
\hline & & Coefficient & 605 \\
\hline & & $\begin{array}{l}\text { Sig. (2-talled) } \\
\mathrm{N}\end{array}$ & .005 \\
\hline
\end{tabular}

** Correlation is significant at the 0.01 level (2-tailed).

Difference of study strategies of high score group and low score group in the college entrance examination are seen in table 5 and 6(Note: English scores are converted into percentile. English scores of low-score group of are less than 60 points while English scores of low-score group are more than 80 points. Each group has selected 60 questionnaires to be analyzed).

Table 5 Feature analysis of learning strategies of low-score group

\begin{tabular}{|c|c|c|c|c|c|c|c|c|}
\hline & & CEE & $\begin{array}{l}\text { Memory } \\
\text { strategies }\end{array}$ & $\begin{array}{l}\text { Cognitive } \\
\text { strategies }\end{array}$ & $\begin{array}{c}\text { Compensation } \\
\text { strategies }\end{array}$ & $\begin{array}{l}\text { Metacognitive } \\
\text { strategies }\end{array}$ & $\begin{array}{l}\text { Affective } \\
\text { strategies }\end{array}$ & $\begin{array}{c}\text { Social } \\
\text { strategies }\end{array}$ \\
\hline \multicolumn{2}{|l|}{$\mathrm{N}$} & 60 & 60 & 60 & 60 & 60 & 60 & 60 \\
\hline \multicolumn{2}{|c|}{ Minimum } & 10.00 & 1.22 & 1.43 & 1.83 & 1.67 & 1.50 & 1.17 \\
\hline \multicolumn{2}{|c|}{ Maximum } & 60.00 & 3.89 & 4.14 & 4.17 & 4.56 & 4.17 & 4.50 \\
\hline \multicolumn{2}{|l|}{ Range } & 50.00 & 2.67 & 2.71 & 2.33 & 2.89 & 2.67 & 3.33 \\
\hline \multicolumn{2}{|l|}{ Mean } & 53.3300 & 2.5611 & 2.8357 & 3.0333 & 3.0852 & 2.8778 & 3.0194 \\
\hline \multicolumn{2}{|c|}{ Std. Deviation } & 9.90352 & .57514 & .59650 & .57637 & .60353 & 62200 & .63712 \\
\hline \multirow[t]{3}{*}{ Percentiles } & 25 & 50.0000 & 2.1111 & 2.4464 & 2.5417 & 2.5556 & 2.3750 & 2.6667 \\
\hline & 50 & 57.0000 & 2.5556 & 2.8571 & 3.1667 & 3.1111 & 2.8333 & 3.0000 \\
\hline & 75 & 60.0000 & 2.9722 & 3.2679 & 3.4583 & 3.5556 & 3.1667 & 3.5000 \\
\hline
\end{tabular}


Table 6 Feature analysis of learning strategies of high-score group

\begin{tabular}{|c|c|c|c|c|c|c|c|c|}
\hline & & CEE & $\begin{array}{l}\text { Memory } \\
\text { strategies }\end{array}$ & $\begin{array}{l}\text { Cognitive } \\
\text { strategies }\end{array}$ & $\begin{array}{c}\text { Compensation } \\
\text { strategies }\end{array}$ & $\begin{array}{l}\text { Metacognitive } \\
\text { strategies }\end{array}$ & $\begin{array}{l}\text { Affective } \\
\text { strategies }\end{array}$ & $\begin{array}{c}\text { Social } \\
\text { strategies }\end{array}$ \\
\hline \multicolumn{2}{|l|}{$\mathrm{N}$} & 60 & 60 & 60 & 60 & 60 & 60 & 60 \\
\hline \multicolumn{2}{|l|}{ Minimum } & 80.00 & 1.56 & 1.79 & 2.00 & 2.00 & 1.33 & 1.17 \\
\hline \multicolumn{2}{|l|}{ Maximum } & 98.00 & 5.00 & 4.57 & 4.83 & 4.78 & 4.67 & 4.83 \\
\hline \multicolumn{2}{|l|}{ Range } & 18.00 & 3.44 & 2.79 & 2.83 & 2.78 & 3.33 & 3.67 \\
\hline \multicolumn{2}{|l|}{ Mean } & 84.7382 & 2.7216 & 3.1268 & 3.4007 & 3.3845 & 2.9213 & 2.9944 \\
\hline \multicolumn{2}{|c|}{ Std. Deviation } & 4.47725 & .65437 & .60175 & .59338 & .69612 & .71866 & .75397 \\
\hline \multirow[t]{3}{*}{ Percentiles } & 25 & 81.0000 & 2.3333 & 2.6429 & 3.0000 & 2.8889 & 2.4167 & 2.5000 \\
\hline & 50 & 84.0000 & 2.6667 & 3.1429 & 3.5000 & 3.3333 & 2.8333 & 3.0000 \\
\hline & 75 & 88.0000 & 3.0000 & 3.6071 & 3.7500 & 4.0000 & 3.5000 & 3.5000 \\
\hline
\end{tabular}

Contrast analysis of the mean of memory strategies of high-score group and low-score group of English scores in college entrance examination are shown in Table 7.

Table 7 Comparison analysis of the mean of memory strategies of low-score group and high-score group

\begin{tabular}{|c|c|c|c|c|}
\hline & & low-score group & high-score group & difference \\
\hline \multirow{2}{*}{ Q1 } & mean & 3.3167 & 3.7978 & \multirow[t]{2}{*}{0.4811} \\
\hline & standard deviation & 1.09686 & 1.07851 & \\
\hline \multirow{2}{*}{$\mathrm{Q} 2$} & mean & 2.6333 & 2.9888 & \multirow[t]{2}{*}{0.3555} \\
\hline & standard deviation & 1.10418 & 1.13312 & \\
\hline \multirow{2}{*}{ Q3 } & mean & 2.6333 & 2.7416 & \multirow{2}{*}{0.1083} \\
\hline & standard deviation & 0.97366 & 1.13346 & \\
\hline \multirow{2}{*}{ Q4 } & mean & 2.8833 & 2.9326 & \multirow[t]{2}{*}{0.0493} \\
\hline & standard deviation & 1.07501 & 1.29508 & \\
\hline \multirow{2}{*}{ Q5 } & mean & 2.7500 & 2.9551 & \multirow[t]{2}{*}{0.2051} \\
\hline & standard deviation & 1.01889 & 1.21459 & \\
\hline \multirow{2}{*}{ Q6 } & mean & 2.8000 & 3.0225 & \multirow[t]{2}{*}{0.2225} \\
\hline & standard deviation & 1.19036 & 1.35661 & \\
\hline \multirow{2}{*}{ Q7 } & mean & 2.2167 & 2.1798 & \multirow[t]{2}{*}{-0.0369} \\
\hline & standard deviation & 1.12131 & 1.22995 & \\
\hline \multirow{2}{*}{ Q8 } & mean & 1.9500 & 2.0337 & \multirow[t]{2}{*}{0.0837} \\
\hline & standard deviation & 0.92837 & 1.13267 & \\
\hline \multirow{2}{*}{ Q9 } & mean & 1.8667 & 1.8427 & \multirow[t]{2}{*}{-0.024} \\
\hline & standard deviation & 0.99943 & 1.12713 & \\
\hline \multirow{2}{*}{$\mathrm{N}$} & effectiveness & 60 & 89 & \\
\hline & missing & 0 & 0 & \\
\hline
\end{tabular}

Contrast analysis of the mean of cognitive strategies of high-score group and low-score group of English scores in college entrance examination are shown in Table 8. 
Table 8 Comparison analysis of the mean of cognitive strategies of low-score group and high-score group

\begin{tabular}{|c|c|c|c|c|}
\hline & & low-score group & high-score group & difference \\
\hline \multirow{2}{*}{ Q10 } & mean & 3.1333 & 3.3371 & \multirow{2}{*}{0.2038} \\
\hline & standard deviation & 0.96492 & 1.02185 & \\
\hline \multirow{2}{*}{ Q11 } & mean & 2.8833 & 3.3820 & \multirow{2}{*}{0.4987} \\
\hline & standard deviation & 1.18023 & 1.18231 & \\
\hline \multirow{2}{*}{ Q12 } & mean & 3.2000 & 3.6404 & \multirow{2}{*}{0.4404} \\
\hline & standard deviation & 1.10162 & 1.05795 & \\
\hline \multirow{2}{*}{ Q13 } & mean & 2.7000 & 3.2022 & \multirow{2}{*}{0.5022} \\
\hline & standard deviation & 0.90760 & 1.05722 & \\
\hline \multirow{2}{*}{ Q14 } & mean & 2.2000 & 2.4831 & \multirow{2}{*}{0.2831} \\
\hline & standard deviation & 0.93519 & 1.04569 & \\
\hline \multirow{2}{*}{ Q15 } & mean & 3.4667 & 3.7303 & \multirow{2}{*}{0.2636} \\
\hline & standard deviation & 1.09648 & 1.11563 & \\
\hline \multirow{2}{*}{ Q16 } & mean & 2.9000 & 3.1685 & \multirow{2}{*}{0.2685} \\
\hline & standard deviation & 1.00338 & 1.05783 & \\
\hline \multirow{2}{*}{ Q17 } & mean & 2.2833 & 2.2921 & \multirow{2}{*}{0.0088} \\
\hline & standard deviation & 1.02662 & 1.07874 & \\
\hline \multirow{2}{*}{ Q18 } & mean & 3.2000 & 3.5843 & \multirow{2}{*}{0.3843} \\
\hline & standard deviation & 1.07040 & 1.04239 & \\
\hline \multirow{2}{*}{ Q19 } & mean & 2.7167 & 2.6180 & \multirow{2}{*}{-0.0987} \\
\hline & standard deviation & 1.05913 & 1.23864 & \\
\hline \multirow{2}{*}{ Q20 } & mean & 3.2667 & 3.4270 & \multirow{2}{*}{0.1603} \\
\hline & standard deviation & 0.86095 & 1.02123 & \\
\hline \multirow{2}{*}{ Q21 } & mean & 2.5667 & 3.2809 & \multirow{2}{*}{0.7142} \\
\hline & standard deviation & 1.03115 & 1.12804 & \\
\hline \multirow{2}{*}{ Q22 } & mean & 2.6333 & 2.7640 & \multirow{2}{*}{0.1307} \\
\hline & standard deviation & 0.82270 & 1.14834 & \\
\hline \multirow{2}{*}{ Q23 } & mean & 2.5500 & 2.8652 & \multirow{2}{*}{0.3152} \\
\hline & standard deviation & 0.99873 & 1.07863 & \\
\hline \multirow{2}{*}{$\mathrm{N}$} & effectiveness & 60 & 89 & \\
\hline & missing & 0 & 0 & \\
\hline
\end{tabular}

Contrast analysis of the mean of compensation strategies of high-score group and low-score group of English scores in college entrance examination are shown in Table 9. 
Table 9 Comparison analysis of the mean of compensation strategies of low-score group and high-score group

\begin{tabular}{|c|c|c|c|c|}
\hline & & low-score group & $\begin{array}{l}\text { high-score } \\
\text { group }\end{array}$ & difference \\
\hline \multirow{2}{*}{ Q24 } & mean & 3.3167 & 3.8427 & \multirow{2}{*}{0.526} \\
\hline & standard deviation & 0.94764 & 0.87774 & \\
\hline \multirow{2}{*}{ Q25 } & mean & 2.7000 & 3.0337 & \multirow{2}{*}{0.3337} \\
\hline & standard deviation & 1.15421 & 1.31814 & \\
\hline \multirow{2}{*}{ Q26 } & mean & 2.1333 & 2.2472 & \multirow{2}{*}{0.1139} \\
\hline & standard deviation & 1.12697 & 1.22735 & \\
\hline \multirow{2}{*}{ Q27 } & mean & 3.2833 & 3.8989 & \multirow{2}{*}{0.6156} \\
\hline & standard deviation & 0.86237 & 0.95400 & \\
\hline \multirow{2}{*}{ Q28 } & mean & 3.0000 & 3.2022 & \multirow{2}{*}{0.2022} \\
\hline & standard deviation & 1.10469 & 1.14990 & \\
\hline \multirow{2}{*}{ Q29 } & mean & 3.7667 & 4.1798 & \multirow{2}{*}{0.4131} \\
\hline & standard deviation & 0.92730 & 0.86026 & \\
\hline \multirow{2}{*}{$\mathrm{N}$} & effectiveness & 60 & 89 & \\
\hline & missing & 0 & 0 & \\
\hline
\end{tabular}

Contrast analysis of the mean of metacognitive strategies of high-score group and low-score group of English scores in college entrance examination are shown in Table 10.

Table 10 Comparison analysis of the mean of

metacognitive strategies of low-score group and high-score group

\begin{tabular}{|c|c|c|c|c|}
\hline & & low-score group & high-score group & difference \\
\hline \multirow{2}{*}{ Q30 } & mean & 2.7333 & 3.0225 & \multirow[t]{2}{*}{0.2892} \\
\hline & standard deviation & 1.05552 & 1.17722 & \\
\hline \multirow{2}{*}{ Q31 } & mean & 2.4333 & 3.0000 & \multirow[t]{2}{*}{0.5667} \\
\hline & standard deviation & 0.90884 & 0.97701 & \\
\hline \multirow{2}{*}{ Q32 } & mean & 2.7000 & 2.9775 & \multirow[t]{2}{*}{0.2775} \\
\hline & standard deviation & 0.86944 & 1.12793 & \\
\hline \multirow{2}{*}{ Q33 } & mean & 3.2833 & 3.4270 & \multirow[t]{2}{*}{0.1437} \\
\hline & standard deviation & 1.07501 & 1.17635 & \\
\hline \multirow{2}{*}{ Q34 } & mean & 3.4333 & 3.7303 & \multirow[t]{2}{*}{0.297} \\
\hline & standard deviation & 0.90884 & 0.98586 & \\
\hline \multirow{2}{*}{ Q35 } & mean & 3.5667 & 3.8090 & \multirow[t]{2}{*}{0.2423} \\
\hline & standard deviation & 0.96316 & 0.95199 & \\
\hline \multirow{2}{*}{ Q36 } & mean & 3.4500 & 3.7528 & \multirow[t]{2}{*}{0.3028} \\
\hline & standard deviation & 0.90993 & 1.03661 & \\
\hline \multirow{2}{*}{ Q37 } & mean & 2.8667 & 3.3258 & \multirow[t]{2}{*}{0.4591} \\
\hline & standard deviation & 0.79119 & 1.01997 & \\
\hline \multirow{2}{*}{ Q38 } & mean & 3.3000 & 3.4157 & \multirow[t]{2}{*}{0.1157} \\
\hline & standard deviation & 0.96199 & 1.07459 & \\
\hline \multirow{2}{*}{$\mathrm{N}$} & effectiveness & 60 & 89 & \\
\hline & missing & 0 & 0 & \\
\hline
\end{tabular}

Contrast analysis of the mean of affective strategies of high-score group and low-score group of 
English scores in college entrance examination are shown in Table 11.

Table 11 Comparison analysis of the mean of affective strategies of low-score group and high-score group

\begin{tabular}{|c|c|c|c|c|}
\hline & & low-score group & high-score group & difference \\
\hline \multirow{2}{*}{ Q39 } & mean & 3.2333 & 3.4831 & \multirow[t]{2}{*}{0.2498} \\
\hline & standard deviation & 1.09115 & 1.13930 & \\
\hline \multirow{2}{*}{ Q40 } & mean & 3.3500 & 3.2921 & \multirow[t]{2}{*}{-0.0579} \\
\hline & standard deviation & 1.02221 & 1.19851 & \\
\hline \multirow{2}{*}{ Q41 } & mean & 2.9000 & 3.0562 & \multirow[t]{2}{*}{0.1562} \\
\hline & standard deviation & 1.17459 & 1.3000 & \\
\hline \multirow{2}{*}{ Q42 } & mean & 2.9333 & 3.1910 & \multirow[t]{2}{*}{0.2577} \\
\hline & standard deviation & 1.05552 & 1.20488 & \\
\hline \multirow{2}{*}{ Q43 } & mean & 1.9833 & 1.7865 & \multirow[t]{2}{*}{-0.1968} \\
\hline & standard deviation & 0.99986 & 0.97085 & \\
\hline \multirow{2}{*}{ Q44 } & mean & 2.8667 & 2.7191 & \multirow[t]{2}{*}{-0.1476} \\
\hline & standard deviation & 0.98233 & 1.11792 & \\
\hline \multirow{2}{*}{$\mathrm{N}$} & effectiveness & 60 & 89 & \\
\hline & missing & 0 & 0 & \\
\hline
\end{tabular}

Contrast analysis of the mean of social strategies of high-score group and low-score group of English scores in college entrance examination are shown in Table 12.

Table 12 Comparison analysis of the mean of social strategies of low-score group and high-score group

\begin{tabular}{|c|c|c|c|c|}
\hline & & low-score group & high-score group & difference \\
\hline \multirow{2}{*}{ Q45 } & mean & 3.5833 & 3.7416 & \multirow[t]{2}{*}{0.1583} \\
\hline & standard deviation & 1.02992 & 1.01722 & \\
\hline \multirow{2}{*}{ Q46 } & mean & 3.3667 & 2.8539 & \multirow[t]{2}{*}{-0.5128} \\
\hline & standard deviation & 0.95610 & 1.20180 & \\
\hline \multirow{2}{*}{ Q47 } & mean & 2.3167 & 2.5506 & \multirow[t]{2}{*}{0.2339} \\
\hline & standard deviation & 0.96536 & 1.10794 & \\
\hline \multirow{2}{*}{ Q48 } & mean & 3.0500 & 2.7528 & \multirow[t]{2}{*}{-0.2972} \\
\hline & standard deviation & 0.98161 & 1.10042 & \\
\hline \multirow{2}{*}{ Q49 } & mean & 2.7000 & 2.7079 & \multirow[t]{2}{*}{0.0079} \\
\hline & standard deviation & 0.96199 & 1.12009 & \\
\hline \multirow{2}{*}{ Q50 } & mean & 3.1000 & 3.3596 & \multirow[t]{2}{*}{0.2596} \\
\hline & standard deviation & 1.08456 & 1.2083 & \\
\hline \multirow{2}{*}{$\mathrm{N}$} & effectiveness & 60 & 89 & \\
\hline & missing & 0 & 0 & \\
\hline
\end{tabular}




\section{Discussion and Analysis}

The results in Table 3 show that the frequencies of the use of different strategies from the highest to the lowest are as follows: compensation strategy, metacognitive strategy, social strategy, cognitive strategy, affective strategy and memory strategy. The table below is in detail (4.5-5.0 means "frequent use"; 3.5-4.4 indicates "regular use "; 2.4-3.4 indicates "general use"; 1.5-2.4 indicates basically no-use).

\begin{tabular}{|c|c|c|}
\hline No. & type of strategies & mean \\
\hline 1 & compensation strategy & 3.2563 \\
\hline 2 & metacognitive strategy & 3.2493 \\
\hline 3 & social strategy & 2.9940 \\
\hline 4 & cognitive strategy & 2.9867 \\
\hline 5 & affective strategy & 2.9289 \\
\hline 6 & memory strategy & 2.6185 \\
\hline
\end{tabular}

Strategies that frequently used are the compensation with average of about 3.26 and metacognitive strategies with average of about 3.24. The average of these two strategies that are used by $75 \%$ of students are higher than 3.67. This shows that the majority of students frequently use compensation strategies (including word speculation, synonym substitution, new-word invention, sign language) and metacognitive strategies (including study-planning, method evaluation, performance thinking and weaknesses-overcoming), etc.

As for social strategy, cognitive strategy and affective strategy, students use these three strategies generally. The average is 2.99 for social strategy, 2.99 for cognitive strategy and 2.93 for affective strategy. It is noteworthy that the mean of the use of social strategy has reached 3.5 for $75 \%$ of students, indicating frequent use of English practice, cultural understanding, seeking correction and English communication and so forth due to bilingual education, international cooperative English teaching, original textbook in English edition and focus on practical English in listening, speaking and writing.

As for the use of cognitive strategies, the average of $75 \%$ of students has reached 3.43 , which is close to the category of "regular use". This shows that students use English review, paradigm search, parsing, speech imitation and English speaking to learn English.

In terms of the use of memory strategies, students generally lack of skills and they are not good at memorization. No matter from the perspective of the mean and percentage, students are considered to be in the category of "generally use because the average has reaches students have reached 2.22 by $25 \%$ of the students. This shows that students rarely use memory strategies of physical performance, repeated reading and spelling, image imagination, rhythm and memory card, etc.

The Results in Table 4 Show That There Is no Significant High Correlation between English Score in College Entrance Examination and Learning Strategies. The descending order of correlation between learning strategies and English achievements from the highest to the lowest are compensation strategy (19.8\%), metacognitive strategy (17.4\%), cognitive strategy (16.7\%), memory strategy $(8.9 \%)$, social strategy $(3.1 \%)$ and affective strategy $(1.8 \%)$. It is noteworthy that the degree of strategy correlation is consistent with the frequency of the use of learning strategies. This can be explained from two aspects: first, the use of strategies and improvement of English have some relevance, but not entirely dependent on the results of English learning strategies. Second, various learning strategies in the system constitute an associated auxiliary complex by means of comprehensive use of each strategy. This also explains that students' English level need to be improved and learning strategies need to be used as a whole.

Results of Contrast Analysis of High Score Group and Low Score Group in Table 5 And 6 Are As Follows: Apart from the mean 2.99 of high score group of social strategy, which is a little 
bit lower than the mean 3.02 of that in low score group, the means of other strategies in high score group are higher than those in low score group. This can reflect that comprehensive flexible learning strategies are useful and can help improve English level to some extent. The mean of memory strategy in high score group is 2.72 while the mean of memory strategy in low score group is 2.56; the mean of cognitive strategy in high score group is 3.13 while the mean of cognitive strategy in high score group is 2.84 ; the mean of compensation strategy in high score group is 3.40 while the mean of compensation strategy in low score group is 3.03; the mean of metacognitive strategy in high score group is 3.38 while the mean of metacognitive strategy in low score group is 3.09 ; the mean of affective strategy in high score group is 2.92 while the mean of affective strategy in low score group is 2.88 .

Regarding to memory strategy, the mean of $75 \%$ of low score group have reached 2.97 while $75 \%$ of high score group have reached 3.0. On the cognitive strategy, the mean of $50 \%$ of low score group have reached 2.86 , the mean of $25 \%$ of low score group have just reached 2.45 while the mean of $75 \%$ of high score group have reached 3.61.On the compensation strategy, the mean of $75 \%$ of low score group have reached 3.46, while the mean of $75 \%$ of high score group have reached the high group reached 3.75. As for affective strategy, the mean of $75 \%$ of the low score group have reached 3.17 while the mean of $75 \%$ of high score group have reached 3.50. These show that cognitive strategy and metacognitive strategy can mainly differ the low score group from the high score group in general.

The Results in Table 7 Show That Low Score Group and High Score Group Usually Use Repeated Reading and Copying For Memory Aid with The Mean of 3.32 And 3.80 Respectively(See Q 1). High score group has reached category of "frequent use". As for other items, both of high score group and low score group have reached the level of general use.

For example, Q2 (the means of sentence memory in low score group and high score group are 2.63 and 2.99 respectively), Q4 (the means of image memory in low score group and high score group are 2.88 and 2.93 respectively), Q5 (the means of scene memory in low score group and high score group are 2.75 and 2.96 respectively), Q6 (the means of rhythm memory in low score group and high score group are 2.80 and 3.02 respectively). It is worth mentioning that in terms of memory card, body language and page (Q7, Q8 and Q9), students don't use them basically. The means of card memory in low score group and high score group are2.22 and 2.18 respectively (see Q7). The means of body language in low score group and high score group are 1.95 and 2.03 respectively (see Q8), and the means of page memory in low score group and high score group are 1.87 and 1.84 respectively (see Q9). All these show that students use relatively simple methods to memorize. They have no cognition for diverse and interesting methods for English learning.

The Results in Table 8 Show That Students of Two Groups Tend to Consider the Unknown with the Link of the Known in Terms of the Use of Cognitive Learning Strategies (Q10, The Mean Is 3.13 for Low Score Group and 3.34 for High Score Group). High score group often practice English pronunciation (Q12 the mean is 3.64 for high score group).Both of two groups often watch English programs (Q15, the mean is 3.47 for low score and 3.73 for high score group respectively) and try to find out English rules (Q20, the mean is and 3.27 for low score group and 3.43 for high score group respectively). Both of the groups like to read English with quick view method (Q18, the mean is 3.20 for low score group and 3.58 for high score group respectively). In addition, both of the two groups say that they will feel pleased due to the interesting content (Q16, the mean is 2.90 for low score group and 3.17 for high score group respectively). Both of two groups rarely use English to make notes and write letters (Q17, the mean is 2.28 for low score group and 2.29 for high score group respectively) and seldom search for words which are similar to new English words in their own language (Q19, the mean is 2.62 for high score group and 2.72 for low score group respectively).

Both of the two groups don't often recite English texts and make reading notes $(\mathrm{Q} 22$, the mean is 2.63 for low score group and 2.76 for high score group respectively) and less frequently (Q23, the 
mean is 2.55 for low score group and 2.87 for high score group respectively). In terms of speaking imitation (Q11), high score group relatively often imitate speaking style and accent of native English speakers (the mean is 2.88 for low score group and 3.38 for high score group respectively). In addition, high score group are more proactive to take initiative to learn English and review regularly (Q13 the mean 2.70 is for low score group and 3.20 for high score group respectively. On the parse $(\mathrm{Q} 21)$, the high score group with the mean of 3.28 is more proficient at parsing than that of low score group with the mean 2.57 .

Table 9 Shows That High Score Achievers Are More Adept At Guessing under Unfamiliar Word and Grammar Circumstance in the Use of Compensation Strategy (Q24, the Mean Is 3.84 for High Score Group). In the method of referring to a dictionary, high score group often read the whole thing instead of reading word by word $(\mathrm{Q} 21$, the mean is 2.57 for low score group and 3.28 for high score group respectively.). Moreover, the high score group is more proficient at guessing English expression of other people than that of the low score group (Q28, the mean is 3.20 for high score group and 3.0 for low score group respectively).In terms of synonym expression, high score achievers are more likely to try synonym replacement than that of low score achievers (Q29, the mean is 3.77 for low score group and 4.18 for high score group respectively). In the use of body language to express meaning, the two groups do not use them skillfully compared with other items (Q25, the mean is 2.70 for low score group and 3.03 for high score group). In the face of English expression barriers, two groups are lacking of flexibility and not good at inventing new words (Q26, the mean is 2.13 for low score group and 2.25 for high score group respectively).

Table 10 Shows That The Means of the Use of Metacognitive Strategies of The Two Groups on the Q33, Q35 and Q38 Are Higher. Two group have set clear goals (Q33, the mean is 3.28 for low score group and 3.43 for high score group respectively); Two groups often overcome learning disadvantages $(\mathrm{Q} 35$, the mean of overcoming learning disadvantage for low score group is 3.57 and 3.81 for high score group respectively) and tend to monitor and adjust to English learning progress (Q38, the mean is 3.30 for low score group and 3.42 for high score group respectively). In contrast, the means of the use of two groups are relatively low in Q30 (the mean of English method is 2.73 for low score group and 3.02 for high score group), Q31 (the mean of English reading control is 2.43 for low score group and 3.0 for high score group) and Q32 (the mean of schedule planning is 2.98 for high score group and 2.70 for low score group). In terms of English methods, students usually lack of diversity due to single source of reading and monotonous practice of textbooks and problem set. Although both of two groups have study goals, they lack of time management, learning detail and mandatory regulation. As for error-correcting (Q34), the average is 3.73 for high score group, which is a little bit higher than that of the low group whose average is 3.43. In terms of exploring English methods (Q36), high score group with the average of 3.75 work harder than that of the low score group with the average of 3.45. In the terms of assessment and improvement (Q37), high score group are better at thinking in English and summarizing the effectiveness of the method with the average of 3.33, which is higher than that of low group whose mean is just 2.87.

Table 11 Show That the High-Score Group with the Average of 3.48 can Relax Mood and Overcome the Fear More than That in the Low Score Group with Average of 3.23 in the Use of Affective Strategies (Q39). The mean of low score group of 3.35 is a little bit higher than that of high score group of 3.29 in the use of self-encouragement (Q40). Both groups are able to do self-encouragement in the fear of misusing English and weak in grade-treating (Q41), pressure concern (Q42), journaling (Q43) and feeling share (Q44) with the category of general use. Students are also less likely to use affective strategies of self-motivation, pressure monitoring, diaries talk and emotional exchanges.

Table 12 Shows That Both of Two Groups Frequently Ask People to Slow Down or Repeat (Q45) and Ask People to Correct Speaking in the Use of Social Strategy with the Mean of 3.58 for Low Score Group and 3.74 for High Score Group (Q46). With regard to seeking help (Q50), the mean is 3.10 for low score group and 3.36 for high score group, indicating students still hope to 
learn authentic language and improve foreign language proficiency through contacts and exchanges.

\section{Conclusions and Implications}

Strategies that are most frequently used by students of international cooperative education program are compensation strategy and metacognitive strategy. Scholar Wen Qiu-fang has clearly stated: "The essence of strategy is the learners' self-awareness and self-learning ability". (Wen Qiufang, Wang Fei, 2004: 102) Teachers can carry out special strategic counseling to help their students to develop life-long self-learning ability of Management strategy which plays a restraining effect on the language learning strategies. The capability of management strategy (ie metacognitive strategy herein) is strong in mobility as it can be effective cross the discipline, time and space. In other words, once the language learners master management strategies skillfully, it is possible for them not only to learn a second language well, but also affect his or her study, work and all aspects of life.”(Wen Qiu-fang, Wang Lifei, 2004a: 11-12). Strategies for English achievement are of some help, teachers should further strengthen students' metacognitive strategy which is the most important thing. Furthermore, English teachers are suggested to balance comprehensive use of learning strategies for a more efficient English teaching and learning.

In the use of memory strategies, teachers can guide students to have divergence imagination, such as making sentences with new words, situation dialogue, physical games, images and imagination in the process of teaching. According psycholinguistics, mutual contact of sensory information is stored together. Image memories of a project could be associated with the same images in other projects. For example, after learning the word "father", it will be very easy to think of "mother", "uncle" or "aunt". After learning the word of "happy", it will be natural to think of happy look or expression. As for the phrase "beautiful long hair / big bright eyes / small round face of students, teachers can guide students to find the rules as follows. The adjective can be divided into commentary and realistic categories. The word "beautiful" belongs to "commentary adjective" and the word "long" belongs to "realistic adjective". "Commentary adjectives" are usually placed ahead of "realistic adjectives". In addition, "realistic adjectives" are roughly placed in the following order: size shape, age, color, origin and material. In order to facilitate memory, some students abbreviate the first letter of these words literally to similar E-mail address: Ssa @ com!

In the use of cognitive strategies, teachers can allow students to imitate language expression in various scenarios. Furthermore, teachers can prepare films, videos and audio-visual materials for students to experience exotic culture, pronunciation and accent. Apart from that, teachers can activate students by communicative teaching, fun reading, regular review of knowledge points, etc.

In the use of compensation strategies, teachers can guide students to predict what they are going to read. In the process of communication and writing, teachers can focus on flexible skills such as hand gesture and new-word invention. In the application of meta-cognitive learning strategy, teachers can guide students to develop concrete and feasible learning objectives and schedule (such as weekly or monthly plan and semester plan), helping students to reflect and summarize their study attitude, performance in class, sentence function, grammar, set goals and effects through quizzes, weekly feedback, monthly assessments, learning diaries, questionnaires surveys, etc. (see table 13) In this way, students are conscious of their learning method and make judgments whether their learning are effective or not so as to adjust and prepare for learning in the future. 
Table 13 Learning Program Evaluation

\begin{tabular}{|l|l|l|}
\hline item of self-assessment & $\begin{array}{l}\text { process of } \\
\text { completion }\end{array}$ & $\begin{array}{l}\text { direction } \\
\text { improvement }\end{array}$ \\
\hline 1.insist on listening to the tape every day & & \\
\hline 2. preview before class & & \\
\hline 3.perform dialogue by cooperating with the students & & \\
\hline 4. participate in class & & \\
\hline 5. number of extracurricular reading & & \\
\hline 6. write dialogue by ourselves & & \\
\hline 7. memorization of vocabulary & & \\
\hline 8.try to write diary in English & & \\
\hline
\end{tabular}

In the use of affective strategies, teachers can encourage students to actively learn from each other and exchange experiences. Therefore students reduce the learning anxiety and learn by analogy in this way. In the use of social policy, teachers can create a good English learning and living environment by advocating English dialogues, so that students develop the habit of thinking in English.

There is no significant high association between the English score and learning strategies. But overall, the means of learning strategies in high score group are higher than those in low score group. It gives us a lesson in the following three aspects: First, the use of strategies is the results of the improvement of language capability while strategies learning may not result in significant improvement. Second, teachers should neither blindly believe in learning strategies not completely abandon the use of learning strategies. It is the comprehensive integrated use of various strategies may result in good English achievements and language proficiency instead of any single learning strategy. Third, the fundamental difference between good learners and poor learners are not the number and frequency of the use of learning strategies, it is the appropriate use of learning strategies that really work. In other words, good learners are good at knowing when, where, how to complete the task and what is the most appropriate learning strategy to be used in different occasions. (Wang Li-fei, 2004). Therefore, teachers should combine teaching content and actual situation with the target courses, language skills, language knowledges, attitudes, learning strategies and cultural awareness. Various activities and practices of language learning are integrated into training task to improve students' awareness and quality of the use of learning strategies.

There are some obvious characteristics for students of international cooperation in education program in the use the language strategy, mainly in the use of social strategy. The average of $75 \%$ of students both in high score group and low score group is 3.5 (category of frequent use). From this, we find that because of the different levels of meta cognitive development, type of cognitive style, motivation, personality, teaching mode, teaching concepts, teaching tasks, assessment methods and teaching atmosphere, students in educational program of international cooperation aim to communicate in the use of learning strategy selection and often to question and doubt bilingual teaching in order to go abroad and take initiative to understand the culture of other countries, especially daily life, social custom, learning environment, language requirements, immigration requirement and job opportunities of cooperative program country so as to form the characteristics of the force of communicative action and ideas.

Improve teachers' level of learning strategies. Teachers who accept professional learning strategy training can give effective instructions and guidance on learning strategies according to various requirements of their students. From the results showed in this paper we know that most teachers are not familiar with the learning strategies actually.

Researcher Cohen (1988) believes that lecture-style training can guide learners to master the use 
of learning strategies on the whole. Cheng Xiao-tang, Zheng Min (2002) have proposed a mandatory-feature lecture of learning strategy training. Specific approaches are as follows: (1) Formulate school rules: the lecture-based learning strategy training is regarded as part of language courses, accounting for a certain percentage of the total score; (2) Learner must attend several seminars of learning strategies; (3) Learners must read a certain amount of articles on language learning strategies; (4) Learners must fill out language diagnostic table of learning strategies;(5) Learner discuss and reflect their own language learning and learning strategies used in the classroom; (6) Learners write a simple report on their own language learning experiences during strategy learning .

All in all, teachers of international cooperative education program should take initiative to adjust and satisfy actual English learning requirement of their students from the training objectives, foundation, curriculum, assessment test, teaching methods, research direction for a more effective English learning and teaching.

\section{References}

[1] Rubin, J. What the "Good Language Learner" Can Teach Us. TESOL Quarterly, 1975, (9):41-5.

[2] O’Malley, J. \& A. Chamot. Learning Strategies in Second Language Acquisition. London: Cambridge University Press, 1990

[3] Oxford, R. L. Language Learning Strategies: What Every Teacher Should Know. New bury House, 1990:156-244.

[4] Wen Qiufang. Methodological Differences between Successful English Learners and Unsuccessful English Learners. Foreign Language Teaching and Research.1995 (3):34-39

[5] Ellis, R. The Study of Second Language Acquisition. Oxford University Press, 1994:264 